\title{
SATELLITE SYMPOSIUM
}

\section{Emerging concepts in the}

management of venous

thromboembolism: the role of bemiparin, a new generation low molecular weight heparin 


\title{
Areas of uncertainty and unresolved issues in the management of venous thromboembolism
}

\author{
R. Abbate \\ General Medical and Cardiology Clinic, University of Florence, Florence, Italy
}

\section{Introduction}

Major advances have been made in the management of venous thromboembolism (VTE) in recent years. The importance of this clinical entity is emphasised by the fact that every year in the United States, deep venous thrombosis (DVT) is diagnosed in nearly half a million people and almost a quarter of a million die as a result of pulmonary embolism (PE). The development of clinical guidelines and new management options together with the discovery of new agents have radically changed the way physicians manage patients with VTE. The 6th Consensus Conference of the American College of Chest Physicians (ACCP) recommended the use of low molecular weight heparins (LMWHs) in the prevention and treatment of VTE and meta-analyses show that LMWHs appear to be safer and more effective than unfractionated heparin (UFH) [1-3]. Despite these major advances, there are many outstanding issues. This presentation focuses on some of the unresolved issues in the management of VTE:

- Acute therapy

- Neglected clinical conditions

- Identification of high-risk patients

\section{Acute therapy of venous thromboembolism}

The ACCP recommends that the use of thrombolytic agents should be strictly tailored to individual needs and rigorously controlled to prevent serious side effects [1]. In a recent dou- ble-blind study in 256 patients with acute PE and pulmonary hypertension or right ventricular dysfunction, 118 patients were randomised to receive heparin plus $100 \mathrm{mg}$ of alteplase and 138 received heparin plus placebo over a period of two hours [4]. The incidence of the primary endpoint (in-hospital death or clinical deterioration requiring an escalation of treatment) was significantly higher in the heparin-plus-placebo group than in the heparin-plus-alteplase group $(\mathrm{p}=0.006)$, and the probability of 30-day event-free survival was higher in the heparin-plus-alteplase group $(\mathrm{p}=0.005)$. Treatment with heparin plus placebo was associated with almost three times the risk of death. When given in conjunction with heparin, alteplase can improve the clinical course in stable patients who have acute PE and can prevent clinical deterioration. Similarly, in a clinical outcome-based meta-analysis of studies comparing thrombolytic and heparin treatment in patients with PE, thrombolysis had a lower composite endpoint of death/recurrence than heparin treatment; however, excessive bleeding was the trade-off for improved efficacy. The authors concluded that a comparative clinical outcome trial of thrombolysis and heparin treatment is warranted in PE patients selected for high risk of death and/or recurrence and low risk of bleeding [5].

Although anticoagulation remains the mainstay of therapy for VTE, vena caval filters are an important alternative when anticoagulants are contraindicated. A review of the literature showed that apart from one randomised trial, the vena caval filter literature consists of consecutive case series. [6]. Vena caval filters represent a potentially important but poorly evaluated

\section{KARGER \\ Fax +41613061234 \\ E-Mail karger@karger.ch}

www.karger.com (c) 2002 S. Karger AG. Basel

1424-8832/02/0326-0395\$18.50/0

Accessibile online at: www.karger.com/journals/pht
Prof. Rosanna Abbate

Dipartimento dell'Area Critica Medico-Chirurgica

Sez. Clinica Medica Generale e Cliniche Specialistiche

Università degli Studi di Firenze

Viale Morgagni 85, 50134 Firenze, Italy Tel/Fax: 0039-55-4279418;

email: r.abbate@dac.unifi.it 
therapeutic modality but randomised trials are required to establish their role in the management of VTE.

\section{Neglected clinical conditions}

\section{Trauma and fractures}

Although the use of prophylaxis for VTE is well established it is still underused in a number of relatively common clinical conditions including trauma, fractures of the lower extremities, pregnancy/childbirth and retinal vein occlusion. VTE is a serious complication in trauma patients with a $>50 \%$ and $0.4-2.0 \%$ risk of VTE and PE, respectively. In patients with multiple traumas, VTE prophylaxis with LMWH (grade 1A) is recommended except when there is a high risk of haemorrhage [1]. Deep vein thrombosis (DVT) appears to occur with moderate frequency after isolated lower extremity fractures and although few prospective studies are available, limited data indicate that DVT rates can be reduced by routine administration of LMWHs.

\section{Pregnancy}

The risk of DVT during pregnancy is estimated at 0.6 per 1000 women younger than 35 years and 1.2 per 1000 women older than 35 years [7]. The diagnosis and management of VTE in pregnancy is complicated and the optimal approach to prevention of DVT in high-risk patients is as yet unclear. Neither UFH nor LMWH cross the placenta, and several studies have shown that these drugs are safe for the foetus [8]. The use of heparin throughout pregnancy is associated with several potential problems, including haemorrhage, heparininduced thrombocytopenia and osteoporosis, but LMWHs have been used successfully in women with VTE with a reduced incidence of heparin-induced thrombocytopenia and osteoporosis [8]. For nursing mothers, heparin and LMWHs are not secreted into breast milk and can be used safely postpartum.

Table 1. Risk factors for venous thrombotic events

\begin{tabular}{ll}
\hline Primary risk factors & Secondary risk factors \\
\hline Major surgery & Congestive heart failure \\
Acute myocardial infarction & $\begin{array}{l}\text { Previous venous thromboembo- } \\
\text { lism }\end{array}$ \\
Major trauma & Immobilization \\
Paralytic stroke & Obesity \\
Cancer & Chronic respiratory failure \\
Spinal cord injury & Increasing age \\
Pelvic fracture & Haematologic disorders \\
& Central venous catheter \\
& Varicose veins \\
& Pregnancy \\
& Estrogen treatment \\
& Hospitalisation \\
\hline
\end{tabular}

\section{Central retinal vein occlusion}

Despite the fact that over 100000 Italians develop retinal vein occlusion each year, very little is known about this condition. In a comprehensive review of the topic, Williamson concluded that the pathogenesis of central retinal vein occlusion still remains to be elucidated but there is evidence for a role for viscosity, raised intraocular pressure, arteriosclerosis, and perhaps thrombosis of the vein [9]. It has been suggested that LMWHs may be effective in this condition but controlled trials are required to validate this therapeutic option.

\section{Identification of high-risk patients}

Risk factors for VTE are outlined in table 1. In surgical patients the occurrence of DVT is affected both by pre-existing factors and those related to the procedure itself. In many patients, multiple risk factors (which are cumulative), may be present. In general, patients at greatest risk are those undergoing major lower extremity orthopaedic surgery and those with major trauma or spinal cord injury.

Although risk factors predisposing patients to VTE have been extensively studied there are still unanswered questions. For example, the role of thrombophilic disorders in increasing the risk of VTE remains to be clarified. Thrombophilic abnormalities include activated protein $\mathrm{C}$ resistance (factor $\mathrm{V}$ Leiden); prothrombin variant 20210A; antiphospholipid antibodies and deficiency or dysfunction of antithrombin, protein C, protein S, or heparin cofactor II [10-13]. Many authors have advocate screening for thrombophilic disorders but evidence for its usefulness is contradictory.

\section{Conclusion}

Each year millions of people experience a VTE with serious clinical and public health implications. LMWH are now well established and there is a large body of evidence demonstrating their safety and efficacy in the prevention and treatment of VTE. Many clinical trials are ongoing to further define the place of LMWHs in therapy including investigating their use in new indications, establishing methods to identify patients at high risk and determining the optimal duration and schedule of administration. Newer LMWH may offer greater opportunities to target specific clinical settings, especially in high risk patients. The development of bemiparin, a second generation LMWHs with unique chemical and pharmacological properties, is a major step forward in the prophylaxis and treatment of VTE. 


\section{References}

1. Geerts WH, Heit JA, Clagett GP, et al. Prevention of venous thromboembolism. Chest 2001;119:132S.

2. Siragusa S, Cosmi B, Piovella F, et al. Lowmolecular-weight heparins and unfractionated heparin in the treatment of patients with acute venous thromboembolism: results of a metaanalysis. Am J Med 1996;100(3):269-277.

3. Lensing AW, Prins MH, Davidson BL, et al Treatment of deep venous thrombosis with low-molecular-weight heparins: a meta-analysis. Arch Intern Med 1995;155(6):601-607.

4. Konstantinides S, Geibel A, Heusel G, Heinrich F, Kasper W. Heparin plus alteplase compared with heparin alone in patients with submassive pulmonary embolism. N Engl J
Med. 2002;347(15):1143-1150.

5. Agnelli G, Becattini C, Kirschstein $\mathrm{T}$. Thrombolysis vs heparin in the treatment of pulmonary embolism: a clinical outcomebased meta-analysis. Arch Intern Med 2002;162(22):2537-2541.

6. Streiff MB. Vena caval filters: a comprehensive review. Blood 2000;95(12):3669-3677.

7. Greer IA. Thrombosis in pregnancy: maternal and fetal issues. Lancet. 1999;353:1258-1264.

8. Ginsberg JS, Greer I, Hirsh J. Use of antithrombotic agents during pregnancy. Chest. 2001;119:122S-131S.

9. Williamson TH. Central retinal vein occlusion: what's the story? $\mathrm{Br} \mathrm{J}$ Ophthalmol 1997;81:698-704.
10. De Stefano, V, Finazzi, G, Mannucci, PM Inherited thrombophilia: pathogenesis, clinical syndromes, and management. Blood 1996;87:3531-3544.

11. Lane, DA, Mannucci, PM, Bauer, KA, et al. Inherited thrombophilia: Part 1. Thromb Haemost 1996;76:651-662.

12. Lane, DA, Mannucci, PM, Bauer, KA, et al Inherited thrombophilia: Part 2. Thromb Haemost 1996;76:824-834.

13. Bick RL, Kaplan H. Syndromes of thrombosis and hypercoagulability: congenital and acquired thrombophilias. Clin Appl Thrombosis/Hemostasis 1998;4:25-50. 